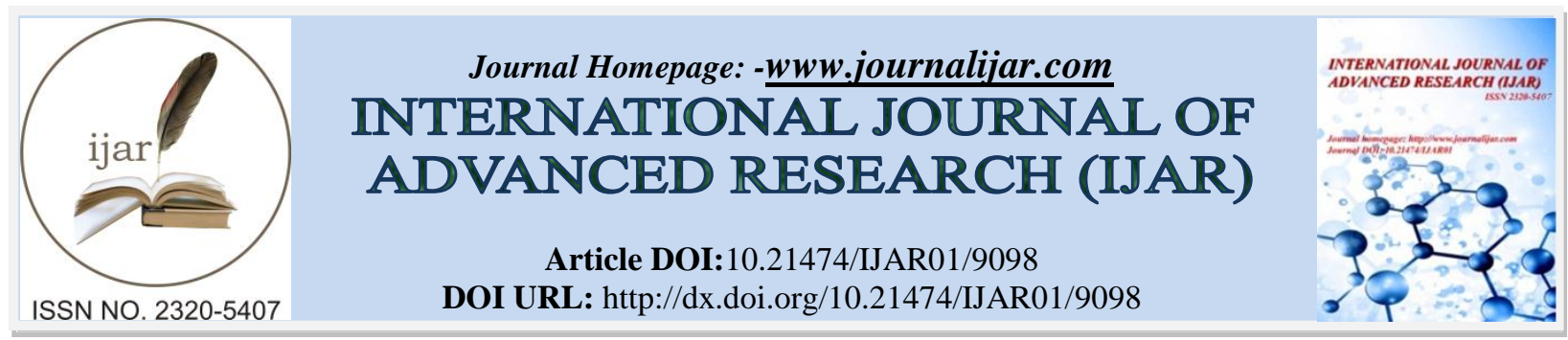

RESEARCH ARTICLE

\title{
IDENTIFICATION OF HOARDING BEHAVIOUR \& ITS FEATURES AMONG OLDER ADULTS: COMMUNITY BASED STUDY.
}

Dr. M.S. Vinsi, Mr. Rahul Nigam, Ms. Leena Sharma and Ms. Monika Chaturvedi.

Mental Health Nursing Department, Bombay Hospital College of Nursing, Indore [M.P.]

\section{Manuscript Info}

Manuscript History

Received: 20 March 2019

Final Accepted: 22 April 2019

Published: May 2019

\begin{abstract}
Hoarding is the persistent difficulty discarding or parting with possessions, regardless of their actual value.

Objectives: 1) To investigate three features of hoarding behaviour i.e. clutter, difficulty discarding and excessive acquisition in older adults. 2) To identified gender differences in older adults regarding hoarding behaviour

Methodology: The study was conducted on 60 older adults in selected urban area. Data collected through socio demographic variables and Saving Inventory-Revised Scale (23 items).

Results hoarding behaviours were identified in older adults and excessive acquisition was the major issue in older adults. The current study shows that there was no significant difference in male and female older adults mean score regarding hoarding behaviour.

Conclusion: Hoarding behaviour is mainly found in older adults and need better community and mental health services.
\end{abstract}

Copy Right, IJAR, 2019,. All rights reserved.

\section{Introduction:-}

Hoarding Disorder (HD) is defined as the acquisition of and failure to discard a large number of items to the extent that it limits use of one's home and causes functional impairment and distress. HD affects individuals of all ages, but research has shown that symptoms increase in severity with age and that older adults are disproportionally affected by HD. Research on HD has accelerated over the past two decades, but few of these studies have focused specifically on older adults. ${ }^{1}$

Hoarding is public health issue. Compulsive hoarding can lead to health and safety risks to the individual, family, and neighbors, creating a large cost for the community. In one study in Massachusetts, $42 \%$ of hoarders had blocked access to their refrigerator, stove, and bathroom, causing filthy or unsafe living conditions. The overall prevalence of hoarding disorder appears to range between 2 percent and 6 percent. This disorder affects both males and females; however, different samples indicate different prevalence rate for both. Some epidemiological studies indicate a higher prevalence of this disorder in males, whereas clinical samples nearly always report a significantly greater prevalence in females. This may be related to differential rates of males and females seeking treatment for this disorder. $^{2}$

Some of the challenges in treating individuals with hoarding disorder include lack of resources, lack of counselors, and lack of identification and reporting. Nurses are key in the identification of patients with hoarding disorder. Nurses can screen for compulsive hoarding behaviors and make referrals to community and mental health services.

Corresponding Author:-Dr. M.S. Vinsi.

Address:-Mental Health Nursing Department, Bombay Hospital College of Nursing, Indore. 
In fact, the Saving Inventory Revised Scale, Hoarding Rating Scale (HRS) and Clutter Image Rating Scale (CIRS) are screening tools that can be used to identify people at risk for this disorder. ${ }^{2}$

Compulsive hoarding is a difficult disorder with complicated nursing care involving different agencies and care teams. Hoarding disorder may also elicit emotional responses in nurses. It's important for nurse managers in a variety of settings to understand this disorder and its safety consequences to better assist their staff members. Because hoarding disorder not only affects the patient but also the community, the nurse manager is in a prime position to plan for the needs of both. ${ }^{2}$

\section{Literature Review}

A study conducted by Catherine Ayers et al (2013) on Hoarding Disorder in older adults, a multidisciplinary team approach. The outcome of the study was Hoarding Disorder is chronic, progressive, and is complicated by agerelated changes in health and social supports, care management approaches may be useful to manage the physical and mental health issues of older adults with Hoarding Disorder. At present, several communities in the US and Australia are using in-home treatment interventions to manage hoarding symptoms, but none have integrated case management of health issues. ${ }^{1}$

Navkiran S. Mahajan et al (Oct 2014) done hospital based study on Gender differences in clinical presentation of OCD, 30 consecutive cases from each gender i.e. male and female were taken. It was found that males show a higher prevalence of hoarding and sexual obsessions. ${ }^{3}$

\section{Methodology:-}

Quantitative research approach with comparative research design used. The study was conducted in selected urban area and the study samples were older adults. The sample size was 60 older adults, 30 samples from each gender i.e. male and female were taken, convenient sampling technique was used. Informed consent was taken from sample and only those consenting to participate in study were involved. Socio demographic data included age group, educational status and marital status. Saving inventory Revised Scale was used to find out the features of hoarding behavior in older adults, three subscales regarding identification of clutter, difficulty discarding and acquisition were used. Total items in SI-R (Saving Inventory-Revised) Scale was 23. For the SIR reverse score items 2 and 4 and sum with the remaining 21 items. Cut off scores at or above 41 indicate hoarding, for analyzing clutter the cut off score at or above 17, regarding difficulty discarding 14 and 9 for excessive acquisition.

\section{Data analysis and interpretation}

Majority of the sample were in the age group of 61-65 (67\%). Most of the samples were married (97\%). Samples mainly were under the category of Literate $(99.7 \%)$.

Objective-I Hoarding behaviours and its features in older adults $n=60$

Table 1:-

\begin{tabular}{|l|l|l|}
\hline \multicolumn{1}{|c|}{ Items } & \multicolumn{1}{c|}{$\mathbf{f}$} \\
\hline Hoarding behavior & 15 & $21 \%$ \\
\hline Clutter & 14 & $20 \%$ \\
\hline Difficulty discarding & 15 & $21 \%$ \\
\hline Acquisition & 27 & $38 \%$ \\
\hline
\end{tabular}

Out of 60 older adults, 15 were identified with hoarding behaviour. There subscale when used, its data revealed that Excessive acquisition was $38 \%$ which is higher when compared to clutter (20\%) and difficulty discarding (21\%)

\section{Objective-II Gender related differences in older adults regarding behaviour.}

1. $\mathrm{H}_{0}$ There will be no significant difference between mean hoarding behavior score of male and female older adults regarding hoarding behaviour.

2. H1There will be significant difference between mean hoarding behavior score of male and female older adults regarding hoarding behaviour.

Mean score of male and female older adults regarding hoarding behaviour 
Table II :-

$\mathrm{n}=60$

\begin{tabular}{|l|l|l|l|l|}
\hline \multicolumn{1}{|c|}{ Gender } & \multicolumn{1}{c|}{ f } & \multicolumn{1}{c|}{ Mean } & t value & P value \\
\hline Male & 29 & 31.9 & \multirow{2}{*}{1.13766} & $* * 0.129971(\mathrm{NS})$ \\
\cline { 1 - 3 } Female & 29 & 34.97 & & \\
\hline
\end{tabular}

*Significant $\mathrm{p}<0.05$

$*$ Not Significant $\mathrm{p}>0.05$

The above table shows that the mean score of male is 31.3 and female mean score is 34.4 . Unpaired test when applied the $\mathbf{t}$ value is 0.129971 which shows that the result is not significant and so null hypothesis is retained.

\section{Findings and Discussion:-}

Current study shows that out of 60 older adults $21 \%$ were having hoarding behaviours (Table -I). Majority of the samples were in the age group of 61-65 (67\%), mainly were married and literate. Study also revealed that among clutter, difficulty discarding and excessive acquisition, the main prominent behaviour issue was excessive acquisition.

Unpaired t test was applied to analyze the significant difference among female and male older adults regarding hoarding behaviour. Findings the statistics results (Table-II) rejected H1 and null hypothesis was retained that there was no impact of gender differences on hoarding behaviour.

\section{Conclusion:-}

Hoarding appears to be more prevalent in older adults. Many studies finding says that this disorder has higher prevalence in male but in present study there was no significant difference in male and female older adults. Compulsive hoarders often fail to seek medical care because of embarrassment about or denial of the disorder. Nurses play a pivot role in screening compulsive hoarding behaviours and make referrals to community and mental health services. Mental health professionals may use family intervention, medications, cognitive behavioral therapy to treat hoarding disorder.

\section{Bibliography:-}

1. Hoarding disorder in older adult: A multidisciplinary team approach, Catherine Ayers, Phd, ABPP, Monika Eckifield Phd, R.N. Scott Makin, Phd, Carol A, Mathews, MD

2. Nursing Mnagement, June 2014, Volume 45 Number6, p 20-26

3. Gender difference in clinical presentation of obsessive compulsive disorder: a hospital based study, Navkiran, S. Mahajan, Akhil Chopara, Ranjive Mahajan, department of psychiatry, Dayanand medical collge and hospital, tangore nagar, Ludhina, India. 